\title{
Conservative treatment of a left atrial intramural hematoma after left atrial thrombus resection and concomitant mitral valve replacement - case report
}

\author{
Dirk Bruegger ${ }^{1 *}$, Sebastian Sadoni ${ }^{2}$, Mikhail Primaychenko ${ }^{2}$, Ralf Sodian ${ }^{2}$, Christoph Schmitz $^{2}$, Bruno Reichart ${ }^{2}$ and \\ Daniel Chappell
}

\begin{abstract}
Left atrial intramural hematoma is a seldom cause of left atrial mass. It has been described to occur spontaneously, after interventional procedures, after blunt chest trauma, or after aortocoronary bypass surgery. We present a case of mitral valve replacement together with the removal of a large intraatrial space-occupying lesion. Intraoperative transesophageal echocardiography confirmed a successful resection of this mass. Surprisingly, upon admission to ICU, transesophageal and transthoracic echocardiography revealed a recurrence of an intramural lesion, closest matching a hematoma, which was confirmed by contrast-enhanced computed tomography. Surgical intervention was thoroughly discussed but a conservative management was favoured. 3 months after surgery, a reassessed transthoracic echocardiography and computed tomography demonstrated an almost complete resolution of the pre-existing hematoma.
\end{abstract}

\section{Background}

Atrial intramural hematomas are severe but rare complications of cardiac surgery and only few cases are described in literature. We present a case of an unexpected intramural left atrial hematoma following mitral valve replacement and concomitant left atrial thrombus resection and the beneficial role of perioperative echocardiography in detecting and monitoring this event.

\section{Case presentation}

A 76-year-old woman with a history of intermittent atrial fibrillation and cerebral infarction with left-sided hemiparesis was admitted to our hospital. Preoperative transesophageal echocardiography revealed a dilated left atrium $(90 \times 80 \mathrm{~mm})$, mitral valve stenosis (mitral valve area $1.04 \mathrm{~cm}^{2}$, transmitral pressure gradient $9 \mathrm{mmHg}$ ), and the presence of a large intracavitary, space-occupying lesion attached to the left atrial roof (Figure 1, Additional file 1).

The patient received mitral valve replacement via left atriotomy with a biological prothesis (Perimount magna

\footnotetext{
* Correspondence: dirk.bruegger@med.uni-muenchen.de 'Department of Anesthesiology, Ludwig-Maximilians-University Munich, Marchioninistrasse 15, 81377 Munich, Germany

Full list of author information is available at the end of the article
}

$27 \mathrm{~mm}$; Edwards Lifesciences, Irvine, CA, USA), extirpation of the intracavitary mass and ligation of the left atrial appendage. Intraoperative transesophageal echocardiography revealed satisfactory valve function and confirmed the successful removal of the intracavitary lesion. Histopathological examination revealed a spherical mass which was subsequently confirmed to be a partially calcified and connective tissue-organized thrombus.

Surprisingly, upon admission to ICU echocardiography revealed a reappearance of a new homogenous mass arising from the left atrial wall (Figure 2, Additional file 2). Neither cardiac output nor ejection fraction were significantly influenced by the hematoma. Contrast-enhanced computed tomography was performed and showed a hyperdense, even bordered, intramural hematoma in the left dorso-basal atrium subtotally obstructing the left atrial chamber (Figure 3, Additional file 3). Surgical intervention was thoroughly discussed interdisciplinary but in the light of the patient's hemodynamic stability and the high risk of dissection of the atrial wall at the auriculoventricular annulus, the risk-benefit analysis favoured a conservative management. Therapeutic dose of intravenous unfractionated heparin was started without a bolus 24 hours after surgery with a target PTT value of 50 seconds. Heparin 


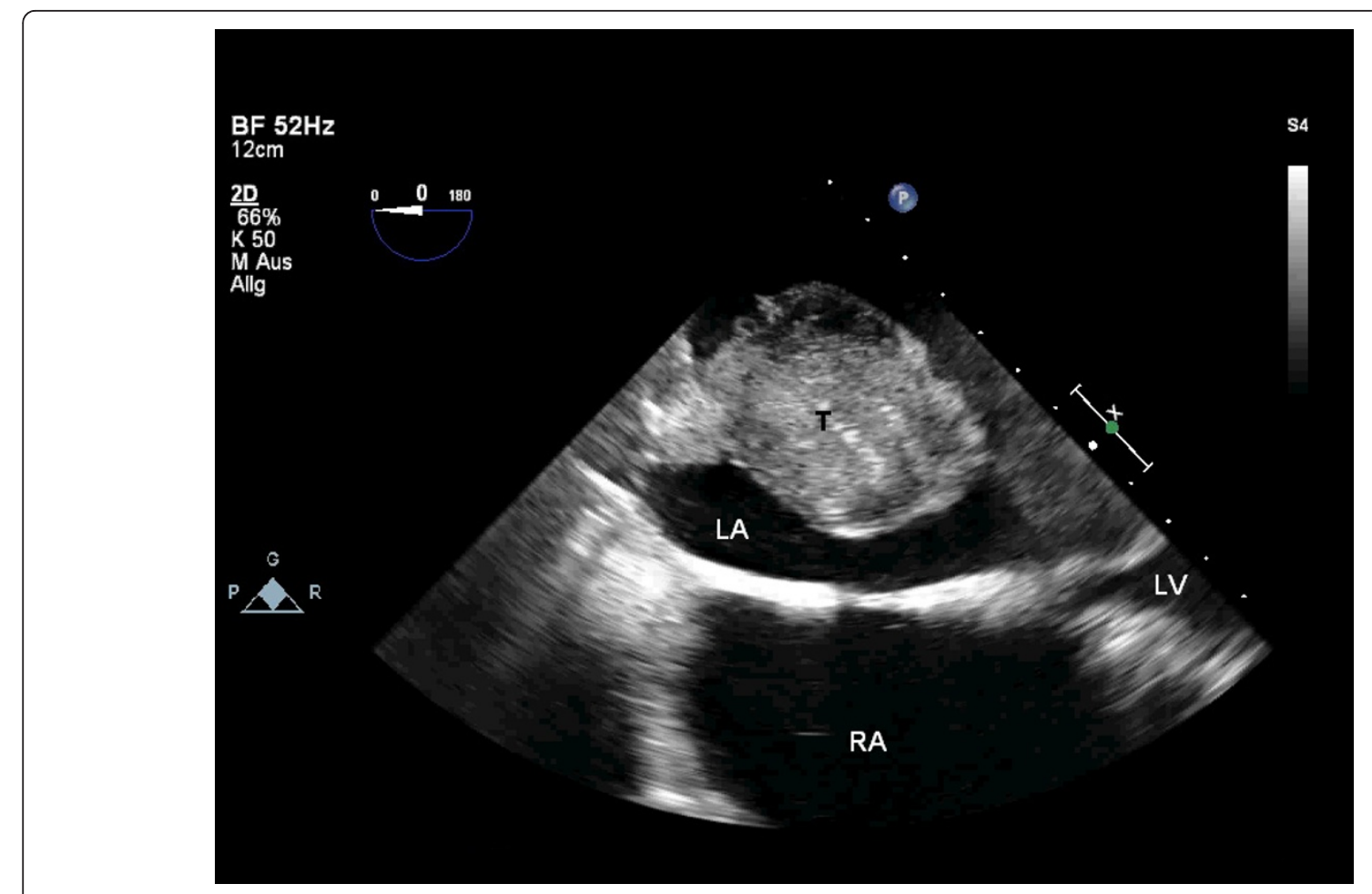

Figure 1 Preoperative transesophageal echocardiogram demonstrating a voluminous intracavitary mass $(58 \times 45 \mathrm{~mm})$ attached to the left atrial roof. T: thrombus; LA: left atrium; LV: left ventricle; RA: right atrium.

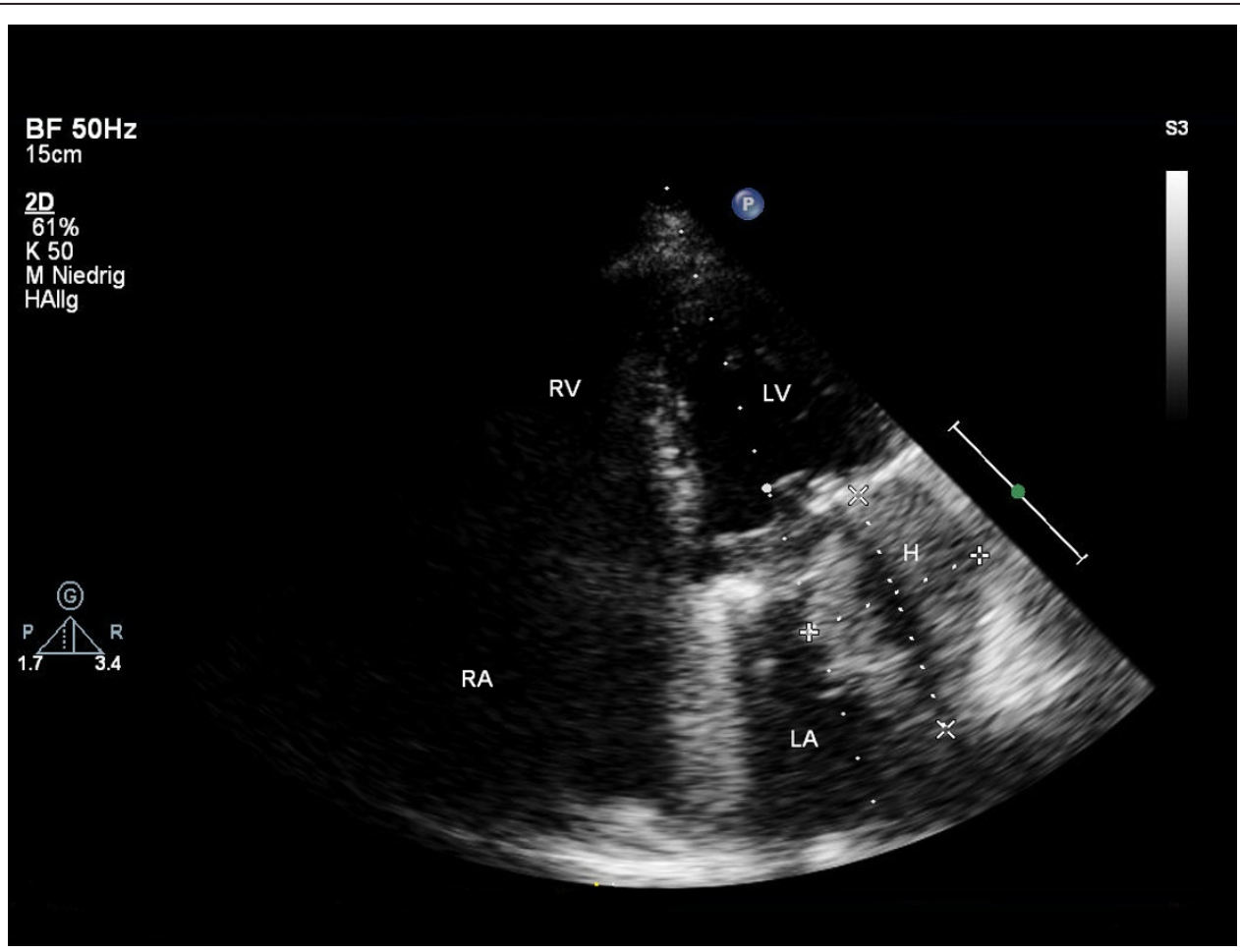

Figure 2 Postoperative transthoracic echocardiogram, apical 4-chamber view, showing development of an echogenic mass (54 $\times 40 \mathrm{~mm}$ ) compatible with an intramural left atrial hematoma. RV: right ventricle; LV: left ventricle; RA: right atrium; LA: left atrium; H: intramural hematoma. 


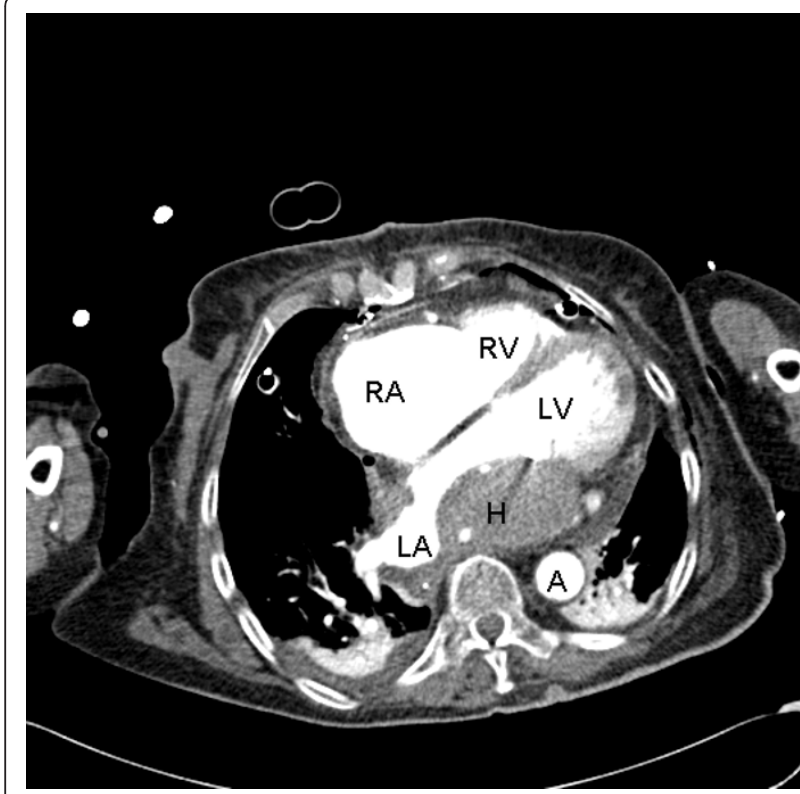

Figure 3 Postoperative contrast-enhanced computed tomography scan confirming development of a large intramural hematoma almost obliterating the left atrial chamber. RA: right atrium; RV: right ventricle; LA: left atrium; LV: left ventricle; $\mathrm{H}$ : intramural hematoma; $\mathrm{A}$ : descending aorta. was continued until an oral anticoagulation therapy with warfarin was in the target INR range of 2.0 to 3.0.

In-house follow up serial echocardiography demonstrated a stable-to-improving left atrial hematoma. A transthoracic echocardiography and contrast-enhanced computed tomography 3 months after surgery revealed an almost complete resolution of the pre-existing hematoma (Figures 4 and 5, Additional files 4 and 5).

\section{Discussion}

Intramural left atrial hematomas are a very uncommon entity, but have been described to occur spontaneously [1-4], after aortocoronary bypass surgery [5], after percutaneous coronary interventions [6,7], radiofrequency catheter ablations [8,9] and after blunt chest trauma [10].

In our case, routine postoperative transesophageal echocardiography revealed an acute $5 \mathrm{~cm}$ diameter intramural hematoma in the left atrium, which could have remained undetected as our patient was asymptomatic. Pre- [11] and intraoperative [12] echocardiography of the heart is an indispensible examination for patients undergoing cardiac valve surgery. Whereas transthoracal echocardiography is less invasive and more convenient to the patient, several studies have demonstrated transesophageal echocardiography to be superior for assessing

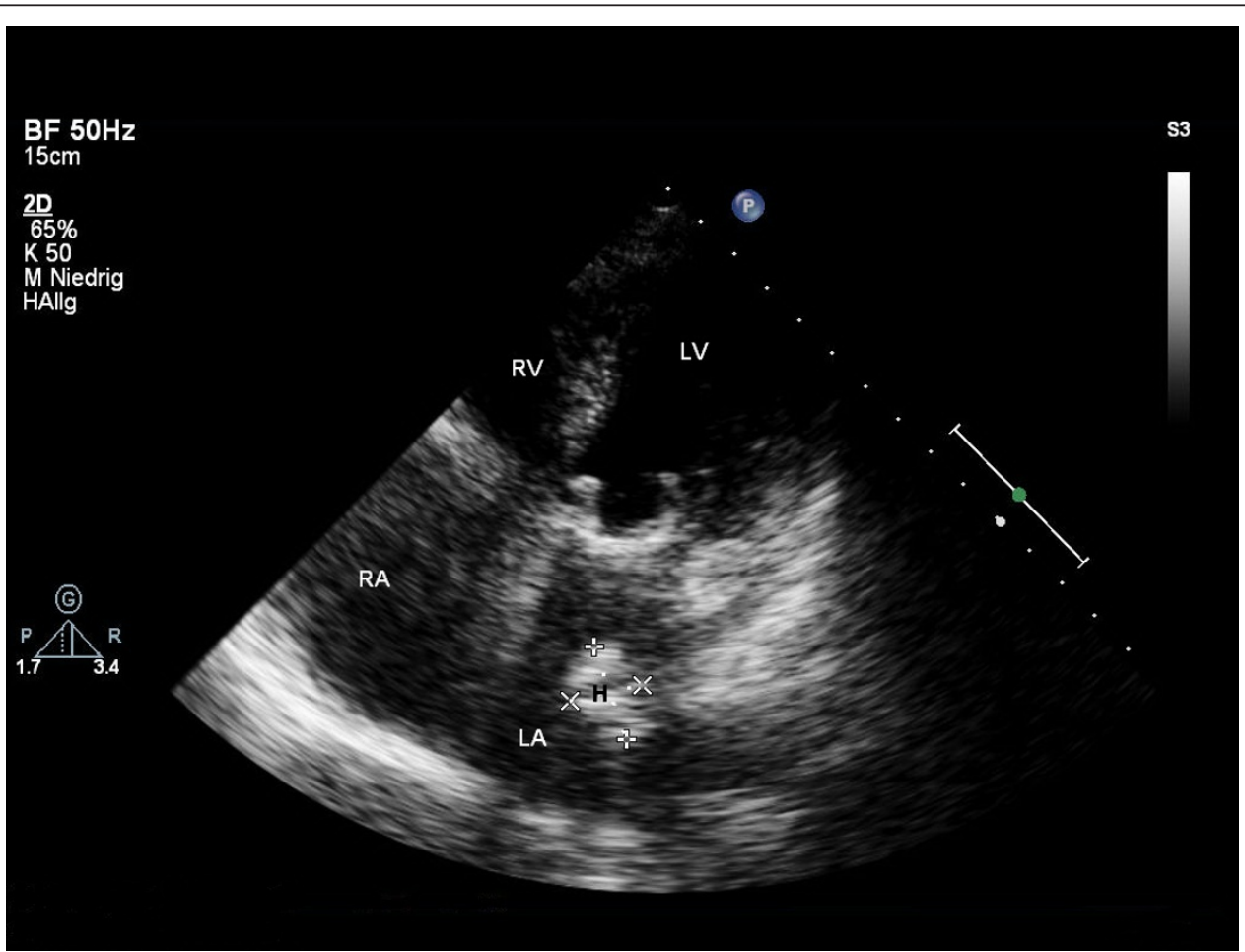

Figure 4 Transthoracic echocardiogram with apical 4-chamber view performed three months following surgery showing a small residual hematoma $(21 \times 16 \mathrm{~mm})$ in the left atrium. RV: right ventricle; LV: left ventricle; RA: right atrium; LA: left atrium; H: intramural hematoma. 


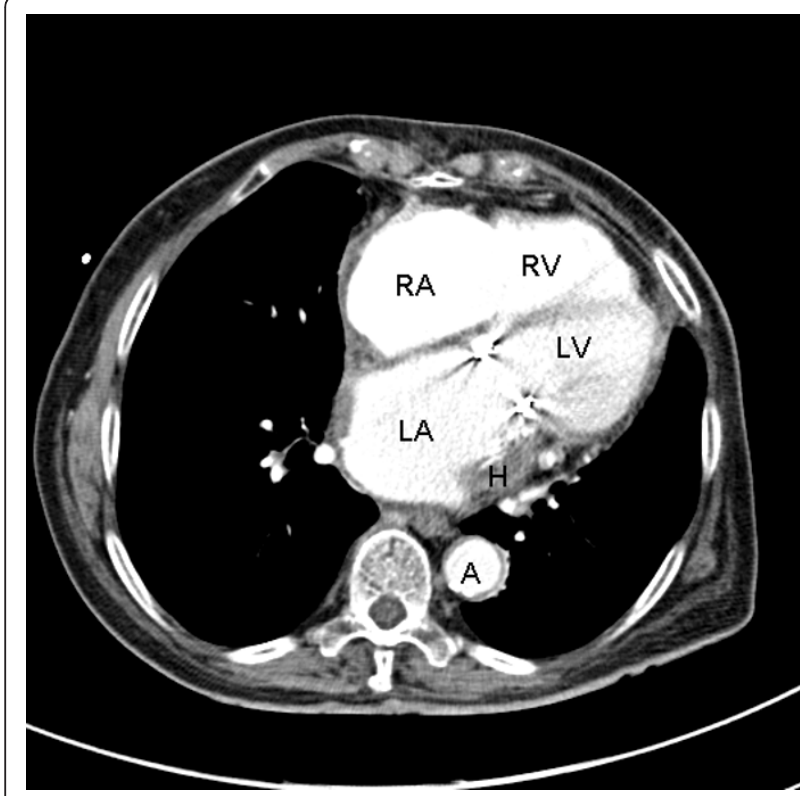

Figure 5 Contrast-enhanced computed tomography scan three months following surgery revealing an almost complete absorption of the intramural hematoma. RA: right atrium; RV: right ventricle; $L A$ : left atrium; $L V$ : left ventricle; $H$ : intramural hematoma; A: descending aorta.

possible sources of cardiac embolism [13], such as intracardiac thrombi or intramural lesions [14]. As in our case, latter can ensure a quick and accurate diagnosis in combination with a computed tomography.

Judging by the spontaneous regression, a conservative approach seemed justified, despite anticoagulation.

\section{Conclusion}

A conservative approach with close-meshed serial echocardiographic examinations in a hemodynamically stable and asymptomatic patient with a left atrial intramural hematoma seems to be an appropriate strategy. This case demonstrates the usefulness and necessity of perioperative echocardiographic imaging in the detection and monitoring of this unexpected event.

\section{Consent}

Written informed consent was obtained from the patient for publication of this case report and any accompanying images. A copy of the written consent is available for review by the Editor-in-Chief of this journal.

\section{Additional material}

Additional file 1: Preoperative transesophageal echocardiogram demonstrating a voluminous intracavitary mass attached to the left atrial roof
Additional file 2: Postoperative transthoracic echocardiogram showing development of an echogenic mass arising from the left atrial wall.

Additional file 3: Postoperative axial CT images.

Additional file 4: Transthoracic echocardiogram three months following surgery revealing an almost complete resolution of the pre-existing hematoma.

Additional file 5: Axial CT images three months following surgery.

\section{Author details}

${ }^{1}$ Department of Anesthesiology, Ludwig-Maximilians-University Munich, Marchioninistrasse 15, 81377 Munich, Germany. ${ }^{2}$ Department of Cardiac Surgery, Ludwig-Maximilians-University Munich, Marchioninistrasse 15, 81377 Munich, Germany.

\section{Authors' contributions}

DB reviewed the case, conducted a review of the literature and drafted the manuscript. SS and MP performed the echocardiographic studies and participated in the design of the case report. RS and CS performed the operation described. BR and DC confirmed the patient's diagnosis and revised the manuscript, contributing important intellectual content. All authors read and approved the final manuscript.

\section{Competing interests}

The authors declare that they have no competing interests.

Received: 30 November 2010 Accepted: 13 April 2011 Published: 13 April 2011

\section{References}

1. Lombardo A, Luciani N, Rizzello V, Natale L, Pennestrí F, Ricci R, Bonomo L, Possati GF, Crea F: Images in cardiovascular medicine. Spontaneous left atrial dissection and hematoma mimicking a cardiac tumor: findings from echocardiography, cardiac computed tomography, magnetic resonance imaging, and pathology. Circulation 2006, 114:e249-250

2. Lanfranchi A, Gelpi G, Rossi RS, Lemma M: A fast-growing obstructive left atrial intramural hematoma causing acute prolonged chest pain. Interact Cardiovasc Thorac Surg 2009, 9:363-365.

3. Shaikh N, Rehman NU, Salazar MF, Grodman RS: Spontaneous intramural atrial hematoma presenting as a left atrial mass. J Am Soc Echocardiogr 1999, 12:1101-1103.

4. Watanabe K, Miguel B, Kemeny JL, Citron B, Camilleri LF: Spontaneous intramural left atrial hematoma associated with systemic amyloidosis. Ann Thorac Surg 2001, 72:2132-2134.

5. Musat I, Hieber C, Kepka A, Novotny P, Poslussny P, Schwarz S, Fitzgerald RD: Intramural left atrial hematoma after aortocoronary artery surgery. Anesth Analg 2003, 97:1605-1607.

6. Tavano D, Carlino M, Pisani M, Colombo A: Images in cardiovascular medicine Conservative treatment of a left atrial hematoma and a localized tamponade occurring during treatment of coronary total occlusion. Circulation 2007, 115:e603-606.

7. Solzbach $U$, Beuter $M$, Haas $H$ : Left atrial intramural hematoma after percutaneous coronary intervention. Int J Cardiol 2010, 141:e37-38.

8. Sah R, Epstein LM, Kwong RY: Images in cardiovascular medicine. Intramural atrial hematoma after catheter ablation for atrial tachyarrhythmias. Circulation 2007, 115:e446-447.

9. Kurek C, Gwechenberger M, Richter B, Binder T, Loewe C, Gössinger H: Intramural left atrial haematoma mimicking cardiac tamponade after catheter ablation of atrial fibrillation. Europace 2009, 11:667-668.

10. Rowe SK, Porter CB: Atrial septal hematoma: two-dimensional echocardiographic findings after blunt chest trauma. Am Heart J 1987 114:650-652

11. Germing A, Mugge A: What the cardiac surgeon needs to know prior to aortic valve surgery: impact of echocardiography. Eur J Cardiothorac Surg 2009, 35:960-964. 
12. Klein AA, Snell A, Nashef SA, Hall RM, Kneeshaw JD, Arrowsmith JE: The impact of intra-operative transoesophageal echocardiography on cardiac surgical practice. Anaesthesia 2009, 64:947-952.

13. De Bruijn SF, Agema WR, Lammers GJ, van der Wall EE, Wolterbeek R, Holman ER, Bollen EL, Bax JJ: Transesophageal echocardiography is superior to transthoracic echocardiography in management of patients of any age with transient ischemic attack or stroke. Stroke 2006, 37:2531-2534.

14. Peters PJ, Reinhardt S: The echocardiographic evaluation of intracardiac masses: a review. J Am Soc Echocardiogr 2006, 19:230-240.

doi:10.1186/1749-8090-6-50

Cite this article as: Bruegger et al: Conservative treatment of a left atrial intramural hematoma after left atrial thrombus resection and concomitant mitral valve replacement - case report. Journal of Cardiothoracic Surgery $20116: 50$.

\section{Submit your next manuscript to BioMed Central} and take full advantage of:

- Convenient online submission

- Thorough peer review

- No space constraints or color figure charges

- Immediate publication on acceptance

- Inclusion in PubMed, CAS, Scopus and Google Scholar

- Research which is freely available for redistribution

Submit your manuscript at www.biomedcentral.com/submit 